University of Louisville

ThinkIR: The University of Louisville's Institutional Repository

Electronic Theses and Dissertations

$12-2014$

\title{
Effects of step training on the kidneys following spinal cord injury in rats.
}

Pradeepa Poudyal

University of Louisville

Follow this and additional works at: https://ir.library.louisville.edu/etd

Part of the Animal Sciences Commons, Animal Structures Commons, and the Physiology Commons

\section{Recommended Citation}

Poudyal, Pradeepa, "Effects of step training on the kidneys following spinal cord injury in rats." (2014). Electronic Theses and Dissertations. Paper 1763.

https://doi.org/10.18297/etd/1763

This Master's Thesis is brought to you for free and open access by ThinkIR: The University of Louisville's Institutional Repository. It has been accepted for inclusion in Electronic Theses and Dissertations by an authorized administrator of ThinkIR: The University of Louisville's Institutional Repository. This title appears here courtesy of the author, who has retained all other copyrights. For more information, please contact thinkir@louisville.edu. 


\title{
EFFECTS OF STEP TRAINING ON THE KIDNEYS FOLLOWING SPINAL CORD INJURY IN RATS
}

\author{
By \\ Pradeepa Poudyal \\ M.B.B.S Calcutta University \\ West Bengal, India.
}

\begin{abstract}
A Thesis
Submitted to the Faculty of the School of Medicine, University of Louisville In Partial Fulfillment of the Requirements

For the Degree of
\end{abstract}

Masters of Science

Department of Anatomical Sciences and Neurobiology University of Louisville. Louisville, Kentucky

December 2014 



\title{
EFFECTS OF STEP TRAINING ON THE KIDNEYS FOLLOWING SPINAL CORD INJURY IN RATS
}

\author{
By \\ Pradeepa Poudyal \\ M.B.B.S., Calcutta University.
}

A Thesis Approved on

November 21, 2014

by the following Thesis Committee:

Dr. Charles Hubscher, PhD.

Thesis Director

Dr. Ashok Kumar, PhD.

Dr. David Stirling, PhD. 


\section{ACKNOWLEDGEMENT}

I would like to express my gratitude to many people who made it possible for me to complete my masters. First, I thank my mentor and advisor Dr. Charles Hubscher for accepting me in his lab, his immense patience and back-up through-out the course. I am also grateful to the other members of Hubscher lab, Jason Fell for teaching me all the procedures and technicalities, Patricia Jill Ward for her guidance, Jim Armstrong and April Herrity for the help with datas, records and numerous other things. I thank Dr. Ashok Kumar, my committee advisor for his guidance and help, Dr. David Stirling for agreeing to serve as one of my committee members and giving me continuous insightful feedbacks to complete my thesis successfully.

I thank Kumar lab and Petruska lab for the use of laboratory facilities. Thank you Ben Harrison for help with imageJ. Thank you Aruna and Gayatri for your help with lab procedures. Thank you Darlene Bruke for data analysis. Thank you Dr. William Dean, and Dr. Christine Schaner Tooley, Biochemistry and Molecular Biology Dept. for your expert advice on western blot result interpretation.

Thank you my parents Sunil and Bulu Poudyal for your undying love and faith, my husband Dipendra for your help and support, my kids Darsh for believing in me, Prakat for bringing humor in life, my brother Bishal and sister Smriti for your moral support. 
I would also like to thank Dr. Jennifer Brueckner and Barbara Hughes for your care and encouragement. Last and the most, someone who really deserves my gratitude, who provided me with her expert assistance, advices and was always there for me in the good and the most difficult times, thank you Sajedah Hindi for being a best friend. Thank you god. 


\section{ABSTRACT \\ EFFECTS OF STEP TRAINING ON THE KIDNEYS FOLLOWING SPINAL CORD INJURY IN RATS \\ Pradeepa Poudyal}

November 21, 2014

Detrusor-sphincter dyssynergia after chronic spinal cord injury (SCl) leads to over-distention, high bladder pressures and vesico-ureteric reflux into the kidney, resulting in repeated infections and pyelonephritis. Given the importance/limited knowledge of $\mathrm{SCl}$ effects on the upper urinary tract, this study assessed expression of two proteins in the kidneys of contused (T9) male rats relative to controls that are indicative of tissue stress/damage (TGF $\beta$, CD11b). The impact of two therapeutic rehabilitation strategies, 60 minutes of step training and general exercise, was then assessed on these protein levels relative to nontrained $\mathrm{SCl}$ controls, plus the effectiveness of a shorter training duration (30 minutes). Western blots revealed a significant decrease in the expression of TGF $\beta$ and a significant increase in CD11b in kidney tissues following SCI. With both types of training and durations, TGF $\beta$ but not CD11b expression returned to normal levels, indicating a benefit of exercise for renal health after chronic SCI. 


\section{TABLE OF CONTENTS}

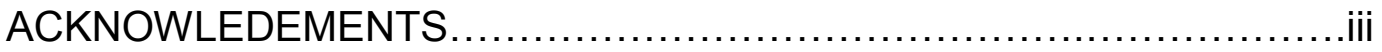

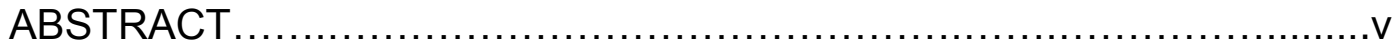

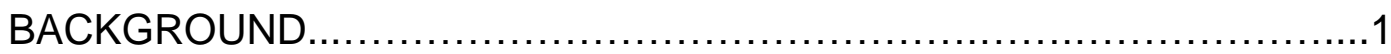

Upper and Lower Urinary Tract Dysfunction after Spinal Cord Injury...........2

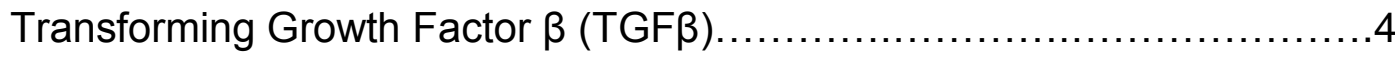

Cluster of Differentiation Molecule 11b (CD11b)............................6

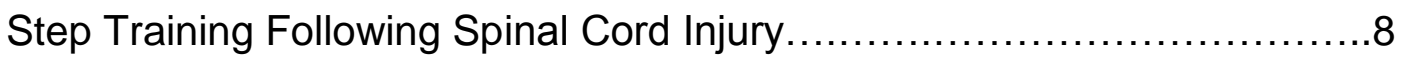

Step Training and Motor Recovery in Animals..................................

Step Training and Motor Recovery in Humans..............................10

Effect of Step Training on Non Locomotor Functions in

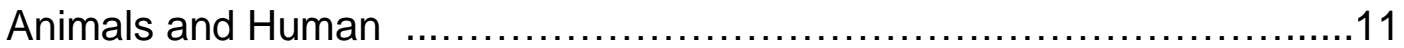

Effect of Step Training on Bladder Functions in

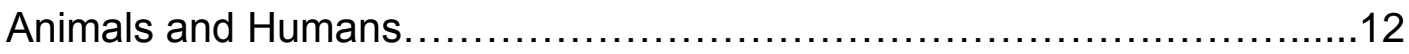

Duration of Step Training In Post Spinal Cord Injury Subjects..............12

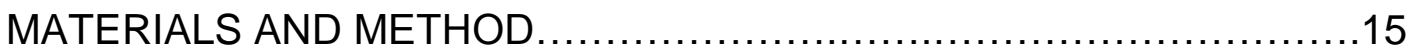

Spinal Cord Injuries.................................................... 15

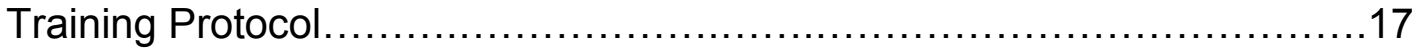

Terminal Studies and Tissue Removal......................................19

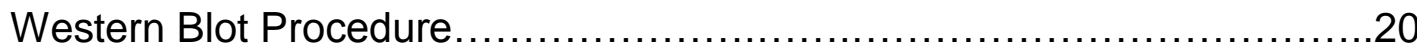

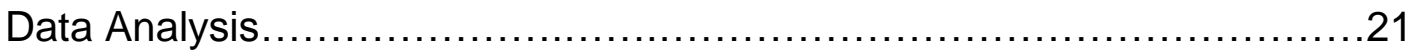

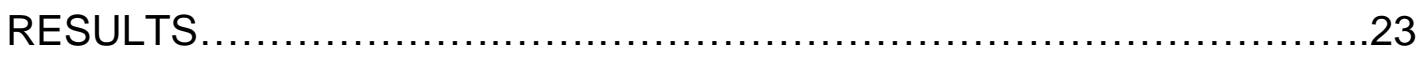

Part 1. Effect of Chronic Spinal Cord Injury on Kidney TGF $\beta$ and

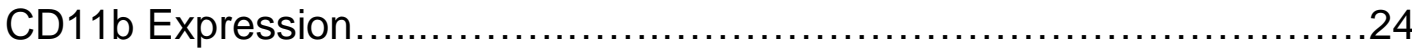


Part 2. Effect of Step Training after Spinal Cord Injury on Kidney

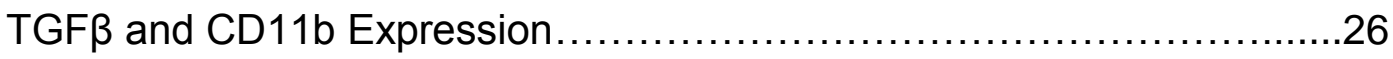

Part 3. Effect of Training Duration after Spinal Cord Injury on Kidney

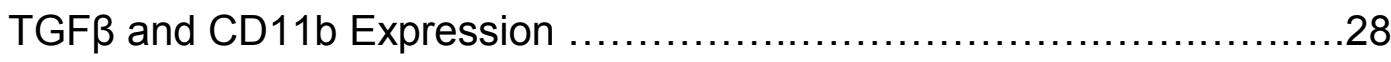

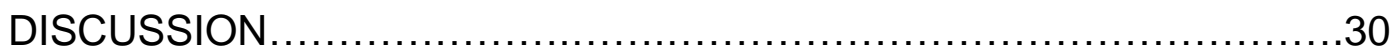

Kidney Function in Spinal Cord Injury ......................................

Kidney Function after Exercise in Spinal Cord Injury .......................35

Impact of Training Duration on Post- Spinal Cord Injury Kidney

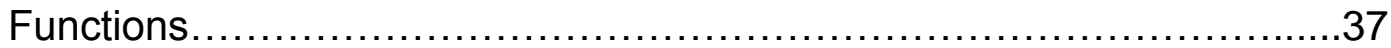

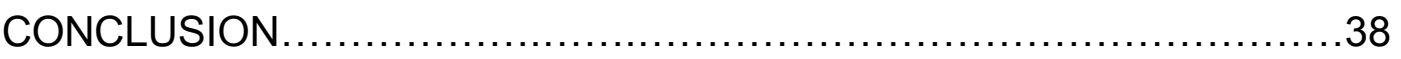

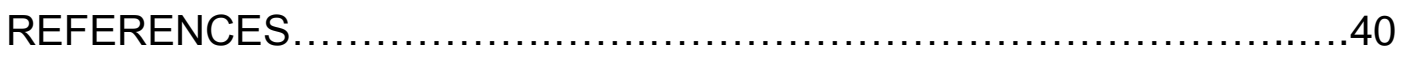

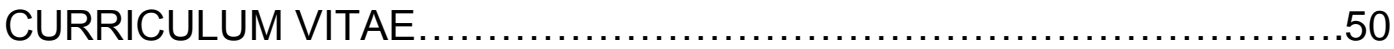




\section{BACKGROUND}

Spinal cord injury (SCl) causes a number of devastating neurological and non-neurological impairments in the body. Current data show that around 273,000 people are living with SCI with about 12,000 new cases occurring each

year (National Spinal Cord Injury Statistical Center, Facts and Figures at a Glance. Birmingham, AL: University of Alabama at Birmingham, March 2013. https://www.nscisc.uab.edu/fact \&figures). Motor paralysis, sensory loss, bladder, bowel and sexual dysfunctions (Ward et al., 2014); (Hubscher and Johnson 2000); (Yoshimura, N. et al. 2014); (Awai and Curt (2014); (Benevento \& Sipski, 2002) are all consequences of the neurological impairments while hypotension, hypothermia (Garstang and Miller-Smith (2007), local and systemic inflammation are among non-neurological problems associated with SCl (Bao, Brown, Dekaban, Omana, and Weaver (2011).

In addition to the primary effects of neurotrauma, such as pain, swelling, bradycardia, and hypothermia (Garstang \& Miller-Smith, 2007), a wide range of secondary effects occur in the acute and chronic phases following $\mathrm{SCl}$ (Bao et al., 2009) ; (Gris, Hamilton, \& Weaver, 2008); (Hausmann, 2003). Primary effects of $\mathrm{SCl}$ are mostly the symptoms of neurological impairments while many secondary events include systemic responses that hinder multi-organ recovery (Dumont et al., 2001) and lead to long term morbidity and an increase in 
mortality. Among many neurological impairments that affect different body functions, one of the most important is dysfunctions of urinary system which is one of the major contributing factors in long term complications and poor quality of life in SCl patients (Hagen, Faerestrand, Hoff, Rekand, \& Gronning, 2011).

\section{Upper and Lower Urinary Tract Dysfunction after SCl}

Post SCl bladder hyper-reflexia and detrusor-sphincter dys-synergia (DSD) causes loss of coordination between bladder and external sphincter and results in disruption of bladder control which may cause reflux to upper urinary tract increasing the risk of chronic upper urinary tract infections (Middleton, Leong, \& Mann, 2008). Kidney failure was one of the leading causes of death in SCl patients in the past (Tribe (1963). However, due to extensive research in the field of bladder management and active interventions in the last 20 years, kidney failure has been reduced dramatically shifting the leading cause of death in SCI to septicemia and pneumonia (National Spinal Cord Injury Statistical Center, Facts and Figures at a Glance. Birmingham, AL: University of Alabama at Birmingham, March 2013. https://www.nscisc.uab.edu/fact\&figures). Even though the mortality rate due to kidney failure has decreased, bladder dysfunction is still one of the major causes of poor quality of life (QoL) (Anderson, 2004) and the main reason for repeated hospitalization of individuals with SCI (Pagliacci et al., 2007)

Although there are some studies on bladder/lower urinary tract dysfunction post-SCl, research on the effects of $\mathrm{SCl}$ on the upper urinary tract and kidneys is 
limited. Proper bladder management reduces the incidence of upper urinary tract complications (Weld, Wall, Mangold, Steere, \& Dmochowski, 2000). However, long standing DSD can cause bladder over-distention with high bladder pressures due to accumulation of urine in the urinary bladder and may lead to vesico-ureteric reflux (V-U reflux) (Ku et al., 2005). Back flow of urine into the kidney each time the bladder contracts initiates multiple complications, including repeated upper tract infections and pyelonephritis; long standing high pressure may lead to hydronephrosis (Cardenas and Hooton (1995) ; (Ku et al., 2005). $\mathrm{SCl}$ patients with neurogenic bladder have high risk of recurrent urinary tract infections and increased risk of developing infections which is made worse by impaired immune functions (Zhang et al., 2013) and frequently used prophylactic antibiotics (Balsara et al., 2013) for prevention of bladder complications in SCI.

Improvement in renal function is highly dependent on proper bladder management but studies have shown that even with careful bladder management, urinary tracts of $\mathrm{SCl}$ rats have increased susceptibility to infection even when they have similar bacterial counts as normal (non-injured) animals (Balsara et al., 2013). Renal insufficiency in SCl subjects has a deleterious effect on the body including the risk to overall health deterioration and kidney failure due to the factors that include fluid imbalance and alteration in drug clearance (of medications used in SCl patients). Also, studies have revealed decreased glomerular filtration rate (Rodriguez-Romero, Cruz-Antonio, FrancoBourland, Guizar-Sahagun, \& Castaneda-Hernandez, 2013) and a decline in renal plasma flow (Kuhlemeier,K.V. et al. 1984) in chronic SCI patients. In 
addition, the adrenal response to exercise and stress is impaired in $\mathrm{SCl}$ (Garstang \& Miller-Smith, 2007).

The incidence of chronic kidney disease is higher in $\mathrm{SCl}$ subjects versus normal individuals (Fischer et al., 2012). Upper urinary tract problems in SCI may or may not be solely due to bladder dysfunction. Impaired immune function and high susceptibility of kidney to infections may also have some negative impacts on overall renal health. Changes in kidney function and/or morphology post-injury is therefore important to investigate. Given the importance and limited knowledge of the effects of SCl on the upper urinary tract (Weld et al., 2000); RodriguezRomero, V.et al. 2013;(Kuhlemeier et al., 1984); (Fischer et al., 2012), the first aim of the current study was to assess the expression of two proteins in the kidneys of $\mathrm{SCl}$ male rats relative to sham controls, whose presence would be indicative of tissue turnover either physiological or pathological (TGF $\beta$ and CD11b; see description below). The second aim was designed to first examine the impact of a therapeutic $\mathrm{SCl}$ intervention, 60 minutes per day of step training on these protein levels relative to non-trained $\mathrm{SCl}$ controls, and then evaluate duration of locomotor training $(\mathrm{LT})$. It is hypothesized that $L T$ improves bladder function and thus lowers the incidence of upper urinary tract complications including the kidney's susceptibility to infections.

\section{Transforming Growth Factor Beta (TGF $\beta$ )}

TGF $\beta$ is a multitask protein, that is widely distributed in the body and plays vital roles in a wide range of functions. Expression of TGF $\beta$ in tissues has varied 
indications. It promotes fibrogenesis, cell apoptosis and tissue healing and suppresses excess cellular proliferation, differentiation and immunity (Moustakas, Pardali, Gaal, \& Heldin, 2002). TGF $\beta$ has 3 isoforms $(1,2 \& 3)$ and works through receptors I and II. It is secreted by all immune cells, including B-Cell, TCell, dendritic cells, and macrophages. It negatively regulates proliferation, differentiation and activation of those cells by other cytokines. Synthesis occurs as a complex with the binding protein LTBP (Latent TGF $\beta$ Binding Protein) in an inactive form (Munger et al., 1997). This complex is activated after receiving signals from an injury site. TGF $\beta$ is released from the latent complex as an activated form as a result of tissue injury or when the system is under stress (Brunner \& Blakytny, 2004). TGF $\beta$ is also important for mobilization of stem cells into the remodeling site and circulation (M. Wan et al., 2012). It is essential for maintaining the tissue homeostasis by repair and regeneration. All three different isoforms of TGF $\beta$ has been found in granulation tissues and hypertrophic scars (Schmid, Itin, Cherry, Bi, \& Cox, 1998). In normal kidneys TGF $\beta$ is expressed predominantly in distal tubules with addition to glomeruli and other tubules, localized in the cytoplasm of tubular epithelial cells and all the isoforms can cause fibrosis (Yu, Border, Huang, \& Noble, 2003);(Goumenos et al., 2002). TGF $\beta$ plays a central role in regulating the mechanism that causes progression of renal disease by promoting the production of extracellular matrix in renal tissue (Border, Okuda, Languino, \& Ruoslahti, 1990) . Regardless of what cause initiates the pathology, final common result of kidney tissue damage is fibrosis (Abbate, M. et al. 2002). Numerous studies on kidney disease have shown that 
expression of TGF $\beta$ is one of the most valuable markers in determining fibrosis in the kidney. As fibrosis is the final step in the kidney pathology and TGF $\beta$, the pro-fibrotic protein is the key factor promoting fibrosis in the kidney (Zhou, Qin, Lei, Zhao, \& Huang, 2012), it is a good marker for assessing kidney tissue stress or damage. Although increased expression of TGF $\beta$ is indicative of the scarring process in the kidney, decreased expression has been associated with a high immune response (Gorelik \& Flavell, 2000). Exacerbation of the immune response or autoimmunity has been reported in association with the absence or decreased expression of TGF $\beta$ (Gorelik \& Flavell, 2000). TGF $\beta$ plays an important role in keeping the immunity in check by exerting an inhibitory influence in the systemic immune response (Wrzesinski, Wan, \& Flavell, 2007).

\section{Cluster of Differentiation Molecule 11b (CD11b)}

CD11b is a member of the integrin family; it is the alpha M subunit of the aMß2 integrin. It is a transmembrane receptor expressed predominantly by monocytes and macrophages and also by several other cells e.g. neutrophils and other granulocytes, natural killer cells, etc. (Kawai et al., 2005). It forms a complex with $\mathrm{CD} 18$ (the $\beta 2$ subunit of the $\alpha \mathrm{M} \beta 2$ integrin) for its migratory function. It also acts as a receptor for fibrinogen (Wright et al., 1988). CD11b is an adhesion molecule which promotes cell-cell adhesion between leucocytes and leucocyte-endothelial cells in inflammation. It is an important mediator of transendothelial leucocyte migration. When a cell is challenged with noxious antigens, it responds by activation of the local and circulatory inflammatory cells depending 
on the extent of the stimuli. The increased expression of CD11b on the surface of inflammatory cells causes migration of these cells to the site of injury which promotes cell-cell adhesion required for phagocytosis. Binding of CD11b to ICAM produces adhesion between inflammatory and endothelial cells which results in influx and migration of cells into target tissues leading to injury due to inflammatory stimuli. Activation of CD11b/CD18 causes the release of inflammatory cytokine thus producing an inflammatory response (Heidari et al., 2014).

$\mathrm{SCI}$ produces a systemic inflammatory response usually after 12 hours of injury and which persists for at-least 3 days. Studies have shown that the major targets of this systemic inflammatory response are lungs, kidneys and liver (Gris et al., 2008). This response is characterized by excessive influx of inflammatory cells mediated by high expression of adhesion molecules ( $\beta 2$ integrins) (Bao, Omana, Brown, \& Weaver, 2012) and oxidative damage in the distant organs (Bao et al., 2009) .The systemic inflammatory response usually subsides within a few weeks but whether it leaves permanent functional disturbances by extensive tissue damage in the affected organs or whether the injury heals without any aftermath is not known. Studies have shown that the activity of systemic inflammatory cells in the kidneys start to decline by the end of 7 days post SCI (Gris et al., 2008) but as mentioned above, the kidneys are at increased risk of developing infections in chronic SCl so it is important to examine the kidneys for inflammatory markers during the chronic stage. Up-regulation in expression of CD11b occurs following inflammation of renal interstitial tissues (Thylen et al., 2000). Increased 
expression of $\mathrm{CD} 11 \mathrm{~b}$ has also been seen with chronic renal failure or in immunedeficient subjects due to activation of mononuclear cells (Zaluska, Ksiazek, and Roliski (2001). By blocking CD11b, damage to the kidney tissue can be mitigated in ischemic reperfusion injury cases (Rabb et al., 1994) as it causes epithelial injury, inflammation and promotes fibrosis (Fujiu, Manabe, \& Nagai, 2011). Thus, over-expression of CD11b in kidney tissue after chronic SCI would indicate that kidneys remain inflicted with some inflammatory activity which may be an after effect of a post $\mathrm{SCl}$ systemic response (increased immune response) even after the systemic inflammatory response has fully subsided.

\section{Step Training following SCI}

Recovery of lost sensory-motor and autonomic functions after $\mathrm{SCl}$ has been a major challenge since alleviating neuropathic pain, regaining independence (locomotor functions in both upper and lower limbs) and restoration of the bladder/bowel functions are the most desired outcomes according to surveys of the SCl population.(Anderson, 2004). Surgical interventions, like decompression and stabilization have shown some promising results in adult human studies but the neurological improvement is limited and outcome depends on the time of surgery (Fehlings et al., 2012), (Fehlings \& Wilson, 2010). Early surgery is more effective in regaining some functions and decreasing complications compared to late surgery (Fehlings \& Wilson, 2010) but due to the lack of sufficient evidence, optimal time of intervention is still controversial (Raslan \& Nemecek, 2012).Surgery is performed more for preventing further direct injury due to 
displacement, improve posture, respiratory functions, reduce pain and to prepare patients for physical therapy (Raslan \& Nemecek, 2012). The ability of CNS tissue to recover and regenerate after injury was realized in the 1980 s contrary to the previous belief (Richardson, McGuinness, \& Aguayo, 1980); (Gimenez y Ribotta, Gaviria, Menet, \& Privat, 2002) . Although studies attempting to regenerate damaged fibers had very little, if any, success in restoring function (Priestley, Ramer, King, McMahon, \& Brown, 2002), studies directed toward enhancing plasticity of surviving neurons and attempts on adaptation with relearning have shown promising effects. (Merkler et al., 2001) ; (Raineteau \& Schwab, 2001). Many studies have been directed towards neuro-rehabilitation as an effective method for recovery of locomotor functions. Selective activation of sensory motor spinal circuits through locomotor training $(\mathrm{LT})$ produces rearrangement of remaining neuronal circuits and improves motor functions (Goldshmit, Lythgo, Galea, \& Turnley, 2008). Task specific LT improves supraspinal plasticity in motor centers by reorganization and helps recover over ground locomotor functions in incomplete SCI patients (Winchester et al., 2005), (S. Harkema et al., 2011) . A recent study suggests that LT may improve locomotor function and neurovascular remodeling in the lumbar motor region by up regulating neuroplasticity genes and angiogenesis genes (Shin et al., 2014).

\section{Step training and motor recovery in animals}

LT has been extensively studied and regularly used for clinical applications. Unlike surgical interventions, stepping improves post SCI locomotor 
functions regardless of the time of intervention (S. J. Harkema, Schmidt-Read, Lorenz, Edgerton, \& Behrman, 2012). Numerous animal studies have established the effectiveness of locomotor training in regaining motor functions after $\mathrm{SCl}$. For example, gradual recovery of limb functions could be achieved after 2-3 weeks of LT in cats with thoracic SCI (Murphy, Ichiyama, Iwamoto, Mitchell, \& Smith, 2013), improved walking ability with alternating hind-limb steps, body weight support and better plantar placements (De Leon, Hodgson, Roy, \& Edgerton, 1998), (Barbeau \& Rossignol, 1987) as well as improved cardiovascular functions (Murphy et al., 2013). Also, our previous study showed comparable results concerning locomotor function improvement in rats (Ward et al., 2014) .

Step training and motor recovery in Humans

Similar effects on motor functions have been reported from human studies. LT (Gorassini, Norton, Nevett-Duchcherer, Roy, \& Yang, 2009), (Wu, Landry, Schmit, Hornby, \& Yen, 2012), (Wirz et al., 2005) or regular exercise (Behrman \& Harkema, 2000) restores post SCI loss of motor function in limbs. Intensive LT improves over ground motor recovery (Wirz et al., 2005), walking speed and balance (Wu et al., 2012), unsupported walking ability in stationary surface, (Dietz, Colombo, \& Jensen, 1994) limb co-ordination and weight bearing. The effect of LT on adaptation of neuronal circuits and gradual improvement continues for at-least 8 months even after training has been stopped (Hicks \& Ginis, 2008). Regular task-specific training activates particular sensorimotor pathways and reinforces neuronal synapses and circuitry improving 
practiced movements in patients by repetitive learning (Cai et al., 2006), (Edgerton et al., 2008). Human studies have shown that LT improves leg arterial diameter and blood flow (Gorassini et al., 2009), (Nash et al., 1997) which in turn maintains leg mass (Thijssen, Ellenkamp, Smits, \& Hopman, 2006) by preventing muscle wasting.

Effects of step training on non locomotor functions in animals and humans

Besides locomotor functions, LT has shown to improve cardio-respiratory (Turiel et al., 2011) and genito-urinary (Schalow, 2010) functions as well as neuropathic pain (Koltyn, 2000). Neuropathic pain or allodynia (increased sensation to pain stimuli that is normally non noxious) is one of the main causes of poor quality of life (QoL) in this group, interfering with day to day activities and causing general ill health. Several therapeutic interventions have been attempted to alleviate chronic SCl-related pain but only physical therapy, exercise and a few medications have been reported to have positive effects so far (Warms, Turner, Marshall, \& Cardenas, 2002), (Heutink, Post, Wollaars, \& van Asbeck, 2011). LT not only improves locomotor functions but also decreases allodynia. Several animal and human studies have demonstrated that pain tolerance and threshold is increased with regular exercise (Koltyn, 2000), (Stagg et al., 2011) by up regulating endogenous opioids in pain modulating regions of brain stem(Stagg et al., 2011). Rhythmic weight bearing exercise improves allodynia and restores normal sensation within 5 weeks (Hutchinson, Gomez-Pinilla, Crowe, Ying, \& Basso, 2004) 


\section{Effects of step training on bladder functions in animals \& humans}

Recent animal studies have provided evidence of improved bladder bowel functions after treadmill training (Ward et al., 2014) which could be corroborated with reports from human studies (Schalow, 2010), (Horst et al., 2013). Improvement of bladder functions has a number of beneficial outcomes like improved QoL (Sharif, Gammage, Chun, \& Ditor, 2014) and reduced rate of upper tract complications. Our recent study using the rat contusion model showed overall functional recovery after LT (body weight supported gait training) (Ward et al., 2014). The trained group of animals (60 minutes per day for 10 weeks) showed improved locomotor activity, bladder functions as well as alleviation of pain. With the evidence of improved bladder functions after 60 minutes of training, there is a potential for upper urinary tract to also benefit as the improvement in bladder functions decreases the risk of upper tract complications. In the present study, the expression of two different markers in the kidney tissue is examined for possible differences in their expression with and without training compared to surgical sham controls.

\section{Duration of Step Training in Post-SCI subjects}

Due to the effectiveness of physical therapy/LT in patients after SCl, as supported by several studies, exercise has been recommended/prescribed to SCI group as a part of overall therapy (Jacobs \& Nash, 2004), (Bizzarini et al., 2005), (Burr, Shephard, \& Zehr, 2012). LT on a treadmill combined with partial 
body weight support (BWSTT) is a widely accepted and effective mode of nonsurgical neurological intervention for SCI patients today (Barbeau et al., 1999), (Dietz et al., 1994), (Wernig \& Muller, 1992) and is being used routinely to achieve overall health improvement and QoL (Hicks \& Ginis, 2008), (Devillard, Rimaud, Roche, \& Calmels, 2007) . Incomplete SCI patients do better at improving over ground walking with cable-driven robotic resistance training as an adjunct to BWSTT (Wu et al., 2012) .

Different methods, speed, intensity and durations have been attempted and found more or less effective in rehabilitation after $\mathrm{SCl}$. Although manually assisted and robotic treadmill training show no superiority in outcome compared to each (Frood, 2011), (Swinnen, Duerinck, Baeyens, Meeusen, \& Kerckhofs, 2010), (Labruyere \& van Hedel, 2014) intensity and duration have produced different functional outcomes (Jacobs \& Nash, 2004). Though different research groups recommend different training paradigms based upon past animal and human studies, clinicians prefer to apply their own routine according to the individual need. However, the most widely accepted and practiced method of rehabilitation around the world are 1. treadmill training (BWSTT or Robotic); 2. functional electrical stimulation (FES); 3. over ground walking (Christopher and Dana Reeve Foundations, Mayo Clinics. Shepherd Center. Atlanta, GA, Spinal cord injury rehabilitation center, Kessler institute for rehabilitation, New Jersey). Since different studies have successfully demonstrated the effectiveness of LT with different training durations, at least 20 minutes 3-5 times weekly for about 46 weeks has been recommended (Bizzarini et al., 2005). Additionally, some also 
recommend 12 weeks of intensive training (Sharif et al., 2014) with daily duration and intensity modified according to personal need. Past animal and human studies indicate that the training durations ranging from 20 minutes to over 90 minutes, 2-5 days a week for 4 to 12 weeks are all effective in regaining functions after SCl (Wu et al., 2012), (Fritz et al., 2011), (S. J. Harkema, Schmidt-Read, et al., 2012) , (Alexeeva et al., 2011), (Lucareli et al., 2011), (Musselman, Fouad, Misiaszek, \& Yang, 2009), (Dobkin et al., 2006), (Winchester et al., 2005), (Thomas \& Gorassini, 2005), (Wirz et al., 2005) , (Hicks et al., 2005), (Stewart et al., 2004), (Postans, Hasler, Granat, \& Maxwell, 2004), (Field-Fote, 2001). In our previous studies, a longer duration of training (60 minutes) was used for proof of concept for a positive outcome in overall locomotor functions (including significant changes in limb kinematics hind limb flexor-extensor bursting pattern \& gait) as well as micturition (including voiding efficiency, inter-contraction interval and contraction amplitude) and neuropathic pain (Ward et al., 2014). For the current study, a 30 minute training group was also examined to assess if a shorter duration of daily LT will have a comparable outcome on renal health. 


\title{
MATERIALS AND METHODS
}

\begin{abstract}
A total of 52 adult male Wistar rats were used this study which was conducted following the guidelines from National Institute of Health $(\mathrm{NIH})$ and Institutional Animal Care and Use Committee at University of Louisville, School of Medicine. Animals were housed individually in their cages in rooms on a 12 hour light-dark cycle.
\end{abstract}

\section{Spinal Cord Injuries}

Contusion injuries were made at the T9 spinal cord level using the Infinite Horizon Impactor Device (Precision Systems and Instrumentation, LLC; Fairfax Station, VA). Each rat $(\mathrm{SCl}(\mathrm{n}=43))$ was anesthetized with a mixture of Ketamine (Ketoset; Fort Laboratories, Fort Dodge, IA) and Xylazine (AnaSed; Lloyd Laboratories, Shenandoah, IA) at a dose of $80 \mathrm{mg} / \mathrm{kg}$ and $10 \mathrm{mg} / \mathrm{kg}$, respectively (administered intra-peritoneally). Prior to the surgical incision, the area was shaved and scrubbed with chlorhexidine surgical scrub. To prevent the drying of eyes during operative and recovery phase, eyes were lubricated and as a prophylactic treatment, a subcutaneous injection of a single dose of $0.5 \mathrm{ml}$ dual Penicillin (PenJect; The Butler Company, Columbus, $\mathrm{OH}$ ) was given perioperatively. As a prophylactic post-surgical intervention for lower urinary tract 
infection prevention, Gentamycin (GentaFuse; Butler Schein, Dublin, $\mathrm{OH}$ ) at the dose of $5 \mathrm{mg} / \mathrm{kg}$ body weight was administered subcutaneously, once daily for 5 days. For post-operative pain relief, $2.5 \mathrm{mg} / \mathrm{kg}$ Ketoprofen (Ketofen; Fort Dodge Laboratories) was given subcutaneously twice daily with $10 \mathrm{ml}$ of saline for two days.

Surgery was carried out maintaining an aseptic condition. Heating pads to maintain normal body temperature were used as well as post operatively during the recovery phase to prevent hypothermia. Laminectomy was performed at the T8 level to expose the cord (T9). Spinal clamps were used on the spinous processes of the T8 and T10 vertebrae to stabilize the vertebrae during contusion. For the injury, the $\mathrm{IH}$ impactor was used with a force of 210 kilodyn and no dwell time to produce a contusion injury that is severe enough to affect bladder function (Hubscher, Fell, and Gupta (2010), (Ward \& Hubscher, 2012), (Ward et al., 2014). Sham animals ( $n=3$ in total) received only a laminectomy (uninjured controls). Wounds were closed in layers using sutures (Ethicon 4-0 non-absorbable surgical suture) for the muscle and subcutaneous layers and Michel clips were used for the skin. Topical antibiotic was applied on the skin after closing. Post operatively animals were cared for three times a day for assessment of health conditions including signs of pain (such as lack of grooming, hypersensitivity to handling), for bladder emptying, and for general care. 


\section{Training Protocol}

Treadmill step training was started 2 weeks after injury (Ward \& Hubscher, 2012). Animals were either trained for 30 min each day for 6 days a week for 47 to 52 sessions ( $\mathrm{n}=12$ total) at $22 \mathrm{~cm} / \mathrm{sec}$ [Ward et al; 2012] or 58 minutes per day 7 days a week for 81 sessions ( $n=18$ total) [Ward et al; 2014]. During each training period, proper plantar paw placement was insured with full toe extension and no ankle rotation. As the animals gradually gained locomotor ability, they were encouraged to walk on the treadmill independently. Attention was paid for signs of stress (for example, diarrhea, porphyrin stains in eyes or irregular breathing pattern). Sessions were terminated early for any animals showing any signs of stress. Also, if any abrasions were observed on the paw and skin the animals were taken out of the sessions until they healed. Note that for the 60 minute training study animal, an additional surgery was done a week prior to the contusion injuries for implantation of EMG electrodes (Ward et al., 2014). Electrodes were placed surgically on the skull and the wires were inserted in the hind limb muscles (left vastus lateralis, semitendinosus, soleus, and tibialis anterior) for use as part of a different study.

An Exer 3/6 animal treadmill (Columbus Instruments. Columbus, Ohio) was adjusted with side platform and spring scales to fit individual body weights. A lycra vest (Robomedica, Inc., Mission Veijo, CA) was used to harness the animals and the spring scales were clipped on both the ends of the vest. The non-trained ( $n=6 \& n=7$ for the 30 and 60 minute study, respectively) group of male rats received zero body support and remained with the lycra vest harness 
and spring scale beside the treadmill belt (no training performed). These animals were mostly either resting quietly, sleeping, or grooming their face throughout the session. The hind limbs of the forelimb trained group $(n=6 \& n=9$ for the 30 and 60 minute study, respectively) of rats were supported with the spring scale and kept on the platform slightly above the belt preventing the hind limb from touching the treadmill belt while allowing only the fore limb to freely walk on the belt and adjusting the scale to zero body weight support. The quadruped group ( $\mathrm{n}=6$ \& $\mathrm{n}=9$ for the 30 and 60 minute study, respectively) of trained animals walked on the belt harnessed in the vest with two spring scale supports and with manual help from the trainer at the hip and ankle flexors. The trainer periodically adjusted both support and help as required.

For the 58 minute training sessions, multiple speeds were applied with body weight support being adjusted as needed by the trainer (Ward et al., 2014). Briefly, stepping started with "a warm-up period" at a speed of $10 \mathrm{~cm} / \mathrm{s}$ to help the rats adjust to the stepping. The speed was then gradually increased (to 14 $\mathrm{cm} / \mathrm{s}$, then $18 \mathrm{~cm} / \mathrm{s}$ then $22 \mathrm{~cm} / \mathrm{s}$ ) at intervals over a period of 8 minutes. The animals were then trained for 5 minutes at an "adaptability speed" (it is the speed where animal showed proper paw placements with complete toe extension and without the ankle rotation along with forelimb hind limb co-ordination and each animal had different adaptability speed). Minimal assistance from the trainer was required at this speed. The last phase was the "retraining period," where animals went through the whole previous cycle again with about 30 minutes at the speed of $22 \mathrm{~cm} / \mathrm{s}$. Body weight support required by the animal was provided by the 
trainer at hip flexors or by holding the tail. Independent stepping was encouraged when the rats had achieved better co-ordination, stability and absence of hind limb dragging.

\section{Terminal Studies and Tissue Removal}

After completion of the last training session, a trans-vesicle catheter (PE60 tubing with previously heated tip to form a collar of about $2 \mathrm{~mm}$ from the end) was inserted into the bladder through the dome under anesthesia (2\% isofluorane). The tubing was then secured to the bladder with a purse string suture (4-0 Ethilon, which was placed prior to catheter insertion) and connected to an infusion pump and pressure transducer.

Following a two hour recovery period and cystometry assessments of lower urinary tract function, the 30 minute training groups of animals and uninjured control group animals ( 3 surgical shams and 6 age-matched naïve male rats) were given an overdose of $50 \%$ urethane and tissues were systematically removed, including the kidneys. For the 60 minutes study animals, an over dose of Ketamine/Xylazine mixture was given followed immediately by perfusion with heparinized saline then 1X PBS $(1 \mathrm{mg} / \mathrm{ml}$ phosphate buffer solution) followed by $30 \%$ RNA. The left kidney was flash frozen in liquid nitrogen immediately and stored at $-80^{\circ} \mathrm{C}$. The right kidneys were preserved in $4 \%$ paraformaldehyde at $4^{\circ} \mathrm{C}$. 


\section{Western Blot Procedure}

Expression of the proteins TGF $\beta$ and CD11b were analyzed with western blots following our previously published protocols (Gupta \& Hubscher, 2012) . Kidney tissues (left only) were sectioned (so as to include both cortex and medulla in the sample) on an ice tray and homogenized in ice cold lysis buffer [50mM Tris HCL(pH 8.0), 200mM NaCl, 50mM NaF,0.3\%TritonX100,1M DTT,1M Benzamidine, $100 \mathrm{mM}$ Na-orthovanadate, $100 \mathrm{mM}$ PMSF) and protease inhibitor (Halt protease inhibitor single use cocktail Prod\#78425, Thermo Scientific). For protein assay, the Biorad Protein assay reagent was used. Protein estimation was done in a photometer at $590 \mathrm{~nm}$ absorbance. Samples were loaded with $4 \mathrm{X}$ loading buffer (dye) by adjusting the proportion according to the value derived from the estimation. Gels were run in mini protean gel tanks (Bio-Rad mini protean tetra system) in $1.5 \mathrm{~mm}$ pre-cast gels (mini protean TGX gels, Bio-Rad \#456-1083) using 100V for 1.5 hours. The running buffer was 1X Tris-glycineSDS buffer. Protein ladder (Precision plus protein standards, dual color Bio-Rad \#161-0374) was used for the band level detection. Protein was transferred overnight at $30 \mathrm{amp}$ on nitrocellulose membrane (Bio-Rad \#162-0115) in the transfer buffer (1X Tris-glycine-methanol-SDS buffer). Membranes were then blocked in 3\% non-fat dry milk and a TBST solution was applied overnight and washed the next day with TBST. The membranes were then cut at the level of 75 $\mathrm{kDa}$, the upper portion was incubated in Rabbit anti-CD11b (Abcam \#75476) and the lower in Rabbit anti- TGF $\beta$ (Cell signaling \#3711). The membranes were incubated overnight in primary antibody at 1:1000 dilution (diluted in TBST and 
$3 \%$ non- fat dry milk solution) on a mechanical shaker in a cold room. The following day, membranes were incubated in HRP Conjugated anti-rabbit Secondary antibody (cell signaling \#7074) for one hour at room temperature after washing in TBST buffer three times for 5 minutes each on a mechanical shaker. The membranes were treated with HRP antibody detection reagent (HyGlo chemiluminescent) and exposed to autoradiography film (HyBlot autoradiography film, Denville Scientific). B-actin (Cell Signaling \#4967S) was used as a loading control. After exposure for principal proteins, the membranes were stripped and re-probed with rabbit anti B-actin antibody at 1:1000 dilution.

All the samples were run at-least three times and the bands from all the tests were analyzed by inverse densitometry using ImageJ 1.47 (ver. 1.47, NIH) according to our published protocols (Gupta \& Hubscher, 2012). Each individual value was normalized by subtracting the background and dividing the value with corresponding B-actin values (minus background). The mean of control (naïve, shams or non-trained depending on the comparison group) is taken from the final values and each final value from other animals (to be compared) was normalized in percent.

\section{Data Analysis}

The values obtained from the Image $(1.47 \mathrm{v}, \mathrm{NIH})$ program were then analyzed for the various group comparisons. For the calculation, final raw values 
for the proteins were obtained after subtracting the background and dividing the result with the loading control. For the first two parts of the study, each value obtained from the calculation for $\mathrm{SCl}$ and training groups was normalized with the mean value of shams (that is, sham controls were set to a value of 1). For the last part of the study, the average of the 60 min training group was used to normalize the value of 30 min training group. Statistical analysis included one sample t-test, Student t-test, between means with equal or unequal variance as appropriate and one way ANOVA with Tukey HSD post hoc t-tests. All values were expressed with \pm standard deviation (SD). A $p$ value of $\leq .05$ was considered statistically significant.

For the first part of the study, the effects of injury (NT animals) on the expression of the proteins TGF $\beta$ and CD11b in the kidney were assessed relative to the sham control group of animals (NT vs S). In the second part of the study, the effect of training (both fore-limb and quadrupedal) on the expression of the same proteins were assessed relative to shams and $\mathrm{SCI}$ group. For the final part of the study, the effect of training duration was assessed (30 mins was compared with 60 minutes of training - both fore limb and quadrupedal groups i.e. 30 minutes vs 60 minutes). 


\section{RESULTS}

The mean values of force of impaction and the displacement of the impactor did not differ significantly between the randomized groups of animals. In addition, the percentage of white matter sparing in the spinal cord, white matter volume above and below the epicenter, and the final BBB scores did not differ between the injured non trained, fore limb trained and quadruped trained animals. The mean data are presented in Table 1.

\begin{tabular}{lccccc}
\hline Group & $\begin{array}{c}\text { Force } \\
(\text { Kilo Dyne) }\end{array}$ & $\begin{array}{c}\text { Displacement } \\
(\mu \mathrm{m})\end{array}$ & \%WMS & $\begin{array}{c}\text { WM Volume } \\
(\mathrm{mm} 3)\end{array}$ & $\begin{array}{c}\text { Final BBB } \\
\text { Score }\end{array}$ \\
\hline $\begin{array}{l}\text { Injured } \\
\text { (NT) }\end{array}$ & 231.000 & 1468.429 & 16.112 & 12.169 & 10.571 \\
$\begin{array}{l}\text { Forelimb Trained } \\
\text { (FLT) }\end{array}$ & 232.889 & 1440.111 & 18.716 & 11.280 & 10.333 \\
$\begin{array}{l}\text { Quadruped Trained } \\
\text { (Q) }\end{array}$ & 233.111 & 1401.000 & 15.814 & 10.581 & 10.917 \\
\hline
\end{tabular}

Table1. Summary of lesion information. 


\section{Effect of Chronic SCl on Kidney TGF $\beta$ and CD11b Expression}

Expression of the proteins TGF $\beta$ and CD11b were analyzed with western blots using the left kidneys obtained from 3 sham and $7 \mathrm{SCl}$ male rats at $13-14$ week's post-injury/sham surgery. For TGF $\beta$, two different bands were detected. One protein band was located at $25 \mathrm{kDa}$ and the other around $50 \mathrm{kDa}$. These bands represent mature TGF $\beta$ and TGF $\beta$ precursors (known to produce a band between $45-65 \mathrm{kDa}$ ), respectively per the manufacturer's datasheet. The $25 \mathrm{kDa}$ bands (mature) of TGF $\beta$ were analyzed using ImageJ (version 1.47) software. A comparison between the expressions in sham versus injured animals revealed a significant decrease in kidney TGF $\beta$ levels following chronic SCl (see left side of Figure 1). For CD11b, the protein band was detected slightly above $150 \mathrm{kDa}$ (location around $160 \mathrm{kDa}$, per manufacturer's datasheet). A comparison between the expressions in sham versus injured animals revealed a significant increase in kidney CD11b levels following chronic SCl (see right side of Figure 1). 


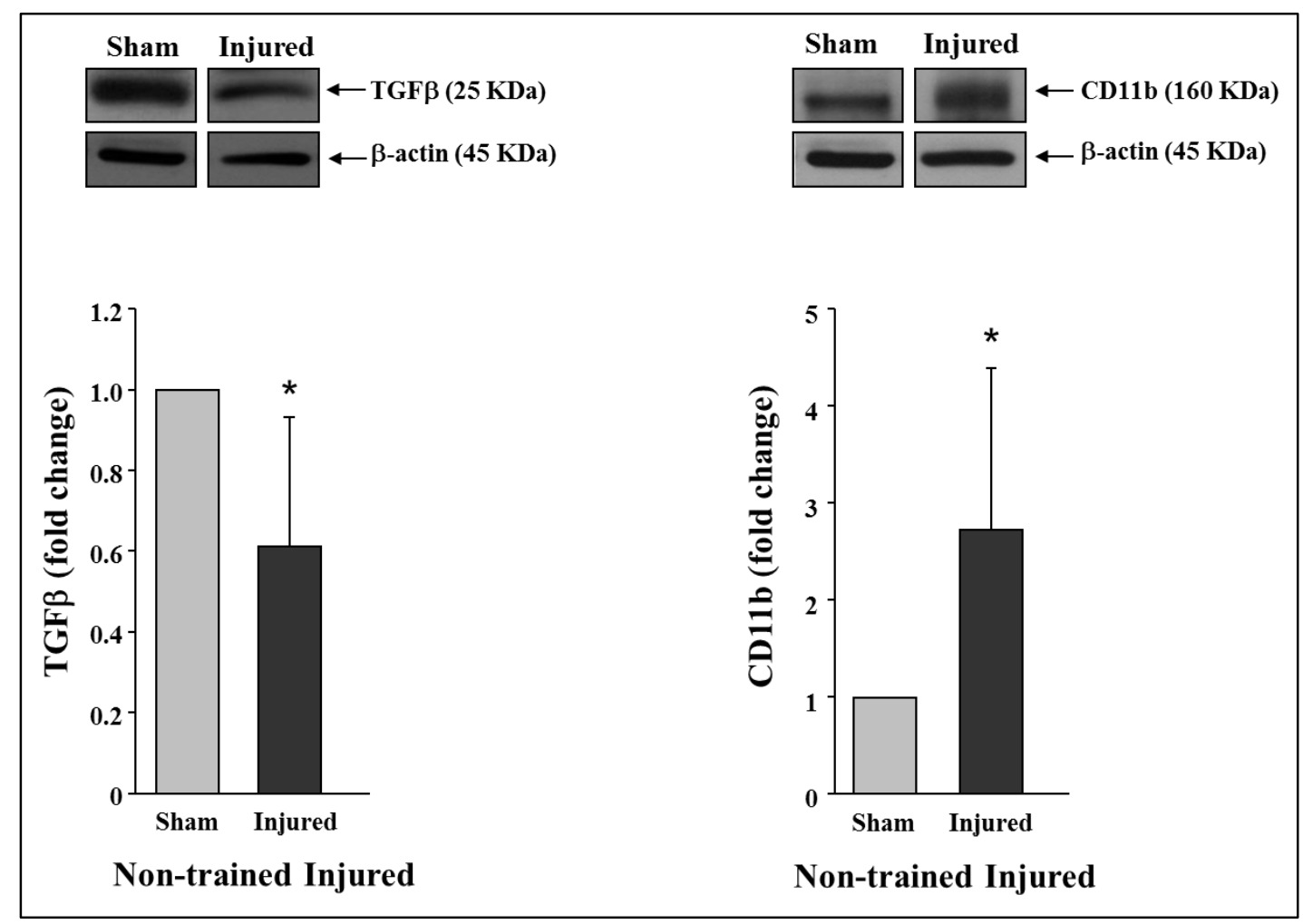

Fig 1: Expression of TGF $\beta$ (left) and CD11b (right) in the kidney of surgical sham and $\mathrm{SCl}$ male rats. Representative blots are at the top and the mean data are graphed at the bottom. ${ }^{*}$ indicates significant difference $(p<.05)$; error bars are standard deviation from the mean. The optical density units of TGF $\beta$ and CD11b bands were normalized after division with respective optical density levels of beta actin ( $\beta$-actin $45 \mathrm{kDa}$ band). 


\section{Effect of Step Training after SCI on Kidney TGF $\beta$ and CD11b Expression}

For the second part of study, the expression of TGF $\beta$ and CD11b protein levels detected in the kidney were compared between surgical shams $(n=3), S C l$ animals (NT - non-trained; $n=7$ ), forelimb trained (FLT; $n=9$ ) $S C l$ male rats (exercise control) and quadrupedal-trained $(Q ; n=9) S C l$ male rats. The training for both groups was daily for 60 minutes beginning two weeks post-SCI for $10-11$ weeks. The significant decrease in expression of TGF $\beta$ in the kidneys for the SCI group was not found following daily training (return to sham levels, regardless of the type of training). In contrast, training had no effect on the SCl-induced increase in the protein expression of CD11b in the kidneys. The findings are provided in Figure 2, which illustrate typical blot examples (2A) and a graphic summary of the data (group means; $2 \mathrm{~B}$ and $2 \mathrm{C}$ ). 


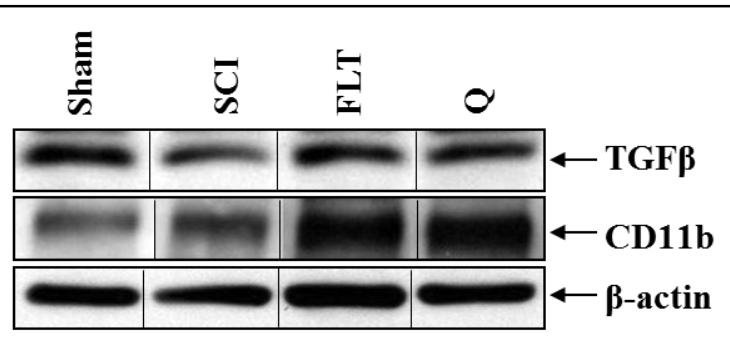

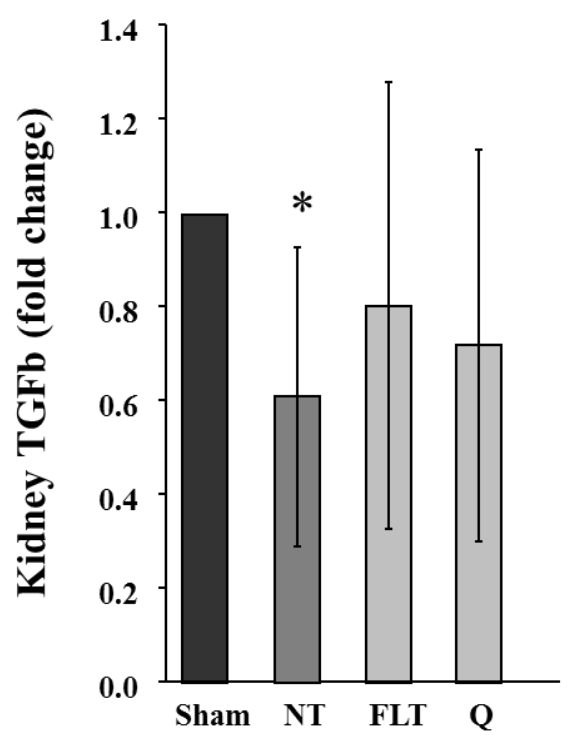

(B)

(A)

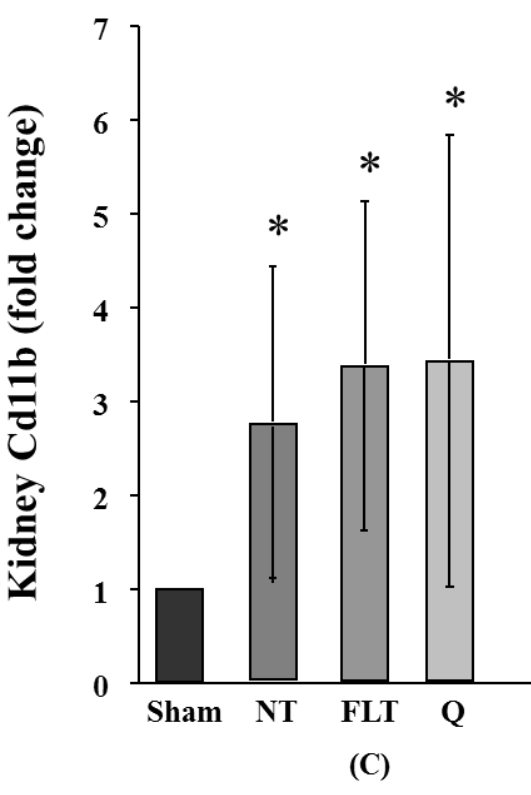

Fig 2: Both fore-limb and quadrupedal training groups (FLT and Q, respectively) showed similar expression of TGF $\beta$ in the kidneys as the sham group (A \& B). Expression of CD11b was significantly higher relative to shams for all $\mathrm{SCl}$ groups, regardless of training (NT = non-trained; $\mathrm{A} \& \mathrm{C}$ ). * indicates significant difference $(p<.05)$; error bars are standard deviation from the mean. 


\section{Effect of Training Duration after SCI on Kidney TGF $\beta$ and CD11b Protein}

\section{Expression}

For the final part of the study, the kidneys were obtained from a group of rats receiving half the daily duration of training, 30 minutes per day $(n=8)$. Western blots for the expression of TGF $\beta$ and CD11b protein levels were run along with the samples from the 60 minute daily trained group $(n=10)$. Note that data from both the forelimb-trained and quadrupedal-trained groups were combined as they did not differ significantly. The results, shown in Figure 3, demonstrate that expression of TGF $\beta$ and CD11b protein did not differ with the shorter duration of training. 


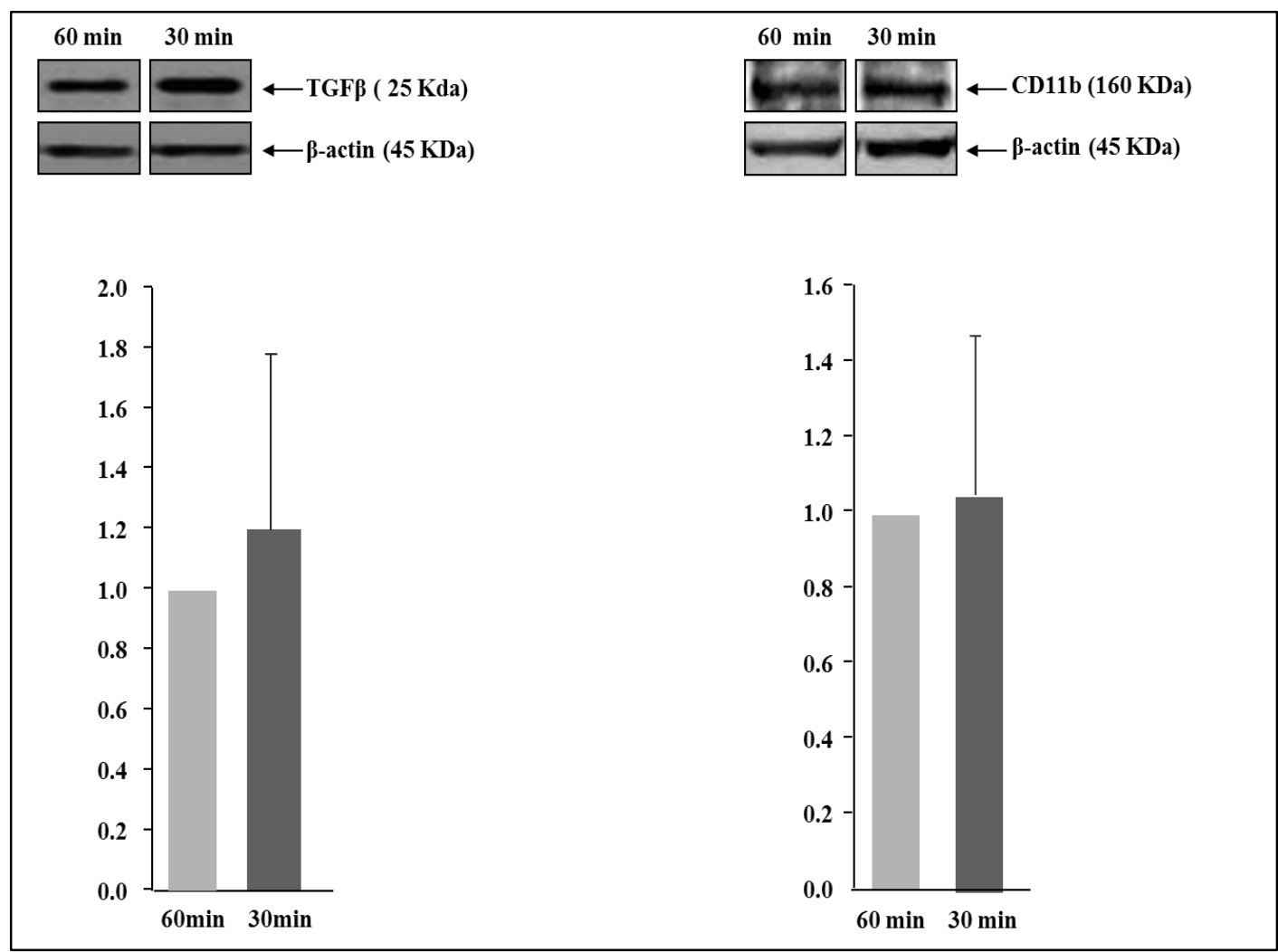

Fig3: A comparison between 60 and 30 minutes of daily training (fore-limb trained and quadruped trained) shows similar expression of TGF $\beta$ (left side) and $\mathrm{CD} 11 \mathrm{~b}$ (right side) in the kidneys of $\mathrm{SCl}$ rats. Note that the comparison is made using 60 min as the standard control. 


\section{DISCUSSION}

The data from the present study demonstrates that after a clinically relevant spinal contusion injury, animals have a significantly lower level of TGF $\beta$ expression in the kidney relative to shams. Since TGF $\beta$ controls T-cell activation and abrogation/abolition of TGF $\beta$ causes gradual infiltration of leucocytes into multiple organs and may result in fatal autoimmunity (Marie, Liggitt, \& Rudensky, 2006); (Gorelik \& Flavell, 2000); (Li, Sanjabi, \& Flavell, 2006) our finding may indicate presence of altered immune function in the kidneys during the chronic phase after SCl. This decrease however may not be enough to cause any pathology in the involved organ. Alternatively, this result may reflect a change in endogenous TGF-beta signaling known to maintain kidney tissue homeostasis. Both 60 minute training $\mathrm{SCl}$ groups had similar levels of protein expression of TGF $\beta$ relative to shams, and 30 minutes of training did not differ.

In addition, there was a corresponding rise of CD11b expression in the kidney after chronic SCI. Study by Basoni et.al. showed that TGF $\beta$ has inhibitory effect on CD11b expression and in absence of TGF $\beta$ there is increased CD11b activity i.e. increased trafficking of leukocytes into the cells resulting in severe tissue wasting syndrome that can be fatal, also increased CD11b expression indicates high trans- endothelial migration of inflammatory cells (Basoni et al., 2005). Since we found no evidence of inflammation in histopathological 
examination (data not shown here), the elevated level of CD11b may be due to the activation of either resident or infiltrating macrophages in the kidney in response to decreased TGF $\beta$ level. Activation of macrophage is required for the synthesis of TGF $\beta$ in the tissues. Macrophages plays a role in both injury and repair in the kidney tissue (Duffield, 2010), so the rise in CD11b expression may as well indicate probable activation of endogenous macrophages for tissue homeostasis. The CD11b finding is consistent with the decreased TGF $\beta$ expression. These findings are also consistent with the number of studies that have established increased inflammatory response and increased susceptibility of kidneys to infection in post SCl subjects (Balsara et al., 2013). However, increased susceptibility of kidneys to infections may not be due to an increased inflammatory response but rather an immune suppression, and lack of t-cell mediated immunity caused by the SCl. Exercise ( 60 and 30 minutes per day) did not have any effect on lowering CD11b expression in the kidneys.

\section{Kidney Function in Spinal Cord Injury}

The kidneys have a rich nerve supply from both the sympathetic and parasympathetic nervous system. Sympathetic fibers come from almost as high as the T6 level to the L2 spinal level (Barajas, Liu, \& Powers, 1992) predominantly through the renal plexus, with an additional supply coming directly or indirectly via the renal plexus from celiac, aortico renal \& lumbar sympathetic ganglions, plexuses and splanchnic nerves. Stimulation of the sympathetic supply causes vaso-constriction and decreased renal blood flow. The 
parasympathetic supply comes from the renal branches of the vagus nerve. In spite of the rich nerve supply, kidney function is mostly controlled by hormones. The four hormones i.e. antidiuretic hormones (ADH), aldosterone, angiotensin II and atrial natriuretic peptide (ANP) regulate kidney functions by controlling osmoregulation and excretion which are the two major functions of the kidney. Thus, the effect of $\mathrm{SCl}$ on the neural circuitry supplying the kidney may not produce any specific functional loss in the kidneys although a disruption in sympathetic outflow (absence of vaso-constrictor effect) may allow increased blood flow into the kidneys and add to the increased leucocyte/macrophage infiltration after SCl. Further studies are needed to test this hypothesis.

The present findings indicate significant changes in the expression of CD11b and TGF $\beta$ in the chronic phase post-SCI. The injury is at the T9 level affecting the major sympathetic outflow to the urinary tract, likely producing vasodilatory effects in the kidneys (direct effect of injury on neural circuitry) along with the systemic immune dysfunction as an indirect effect. Although $\mathrm{SCl}$ pathophysiology is portrayed primarily by cascades of local responses at the site of injury, secondary responses to injury produce concurrent local and systemic inflammation (Gris et al., 2008), (Bao et al., 2012). Circulatory leucocytes produce free radicals, invade visceral organs and activate resident macrophages (Bao et al., 2009), potentially causing damage. In the initial phase of $\mathrm{SCl}$, the predominant inflammatory cells at the site of injury and within the circulation are neutrophils but by 7 days the count starts declining and is taken over by the macrophages (Gris et al., 2008), (Bao et al., 2012). Activation of macrophages 
and other inflammatory cells have been shown to peak between 7 and 28 days post-injury (Popovich, Wei, \& Stokes, 1997). However, increased numbers of macrophages and circulating inflammatory cells have been found in $\mathrm{SCl}$ subjects even after months of injury (Mautes, Weinzierl, Donovan, \& Noble, 2000), (Sinescu et al., 2010).These macrophages are likely to invade organs rich in blood circulation and lead to tissue damage, especially the kidneys and lungs after SCl (Gris et al., 2008), (Bao et al., 2012).

CD11b is expressed by leucocytes and macrophages. High expression of these markers points towards an increased inflammatory response. In the kidney, the predominant inflammatory cells are macrophages (Duffield, 2010). Two different kinds of macrophages have been found in the kidneys, initial inflammatory macrophages (M1) produce an inflammatory response and tissue death by phagocytosis while after the initial phase of tissue destruction, a second type of macrophage (M2) predominates. M2 produces anti-inflammatory cytokines, resolve inflammation, reduce tissue injury and help specialized cells in the kidneys to regenerate after injury. M2 also produces TGF $\beta$ and helps in tissue repair (Fujiu et al., 2011). Secretion of TGF $\beta$ declines gradually after the early phase post-injury and only anti-inflammatory action of M2 is retained (Wang \& Harris, 2011). The current data indicated a high expression of CD11b in the kidneys after chronic injury which implies tissue injury and dysfunction (high expression of CD11b has been found in both acute and chronic kidney diseases) (Al-Saady et al., 1999), (Lu et al., 2008) but since CD11b is also expressed by M2 which is tissue protective, to determine the exact type of macrophage 
responsible for this rise in expression needs further studies. Also, there is evidence to show that even in the presence of activated protective macrophages the ongoing injury or the long standing exposure to activated resident or infiltrating macrophages eventually reverts the healing effects back to injury (Ricardo, van Goor, \& Eddy, 2008) .

In addition, $\mathrm{SCl}$ also is known to trigger systemic autoimmunity (Ankeny, Lucin, Sanders, McGaughy, \& Popovich, 2006). B cells in animal models of SCI start to appear in the circulation as early as 24 hours after injury and continue to proliferate producing notably high titers by 14 days (Ankeny, Guan, \& Popovich, 2009). High titers of pro-inflammatory cytokines produced by $T$ cells and autoantibodies produced by B cells has been found in serum of chronic $\mathrm{SCl}$ human subjects (>12 months post-injury) (Hayes et al., 2002) but whether it is beneficiary or destructive to peripheral tissues has not yet been established. TGF $\beta$ is essential for homeostasis of $T$ cells and B cells. It inhibits the proliferation and differentiation of these cells thus inhibiting the production of inflammatory cytokines from T cells (Marie et al., 2006), (Y. Y. Wan \& Flavell, 2008) and autoantibody as well as antigen receptor expression by B cells (Cazac \& Roes, 2000). Thus, in absence or decline in TGF $\beta$ activity, T cells and B cells can produce deleterious effects. The results of the present study indicate low levels of TGF $\beta$ in the kidneys after chronic $\mathrm{SCl}$, indicative of immune dysfunction. 


\section{Kidney Function after Exercise in Spinal Cord Injury}

It has already been established that locomotor training following $\mathrm{SCl}$ improves multiple aspects of motor function in animal models and human subjects (Behrman, Bowden, \& Nair, 2006; Behrman \& Harkema, 2000), (S. Harkema et al., 2011; S. J. Harkema, Hillyer, et al., 2012; S. J. Harkema, Schmidt-Read, et al., 2012; Martinez, Delivet-Mongrain, \& Rossignol, 2013) . Previous study from our lab with male rats receiving 60 minutes of daily training for 10 weeks showed overall improvement in not only locomotor function but bladder function as well (Ward et al., 2014). The study demonstrated decreased DSD, urethral resistance and as a result increased voiding efficiency and bladder capacity in the contusion rat models. In the present experiments, a positive impact on the expression of TGF $\beta$ has been noted. In both training groups, the level of TGF $\beta$ expression was similar to the levels in surgical sham animals, pointing out the improvement in TGF $\beta$ expression after training. This result implies possible improvement in immune functions with better renal health, (better glomerular filtration rate and kidney function). Improved immune function might decrease the susceptibility of kidneys to repeated infection thus improving QoL of a patient.

The effect of $\mathrm{SCl}$ injury may not be sufficient to produce complete functional loss or organ failure but it definitely hinders spontaneous recovery from the injury due to progressive tissue damage (Oudega, 2013). Spontaneous recovery of locomotor function is known to be affected by immune system disorders after SCI (Ankeny et al., 2009). Exercise has been shown to improve 
immune functions after $\mathrm{SCl}$ but the time of injury and starting of the training as well as the duration and intensity needs to be considered for the most effective strategy on the system and upon recovery (Leicht, Goosey-Tolfrey, \& Bishop, 2013) .

In the present study, CD11b expression levels were elevated for all injury groups, including those that did not receive daily exercise. Persistent high level of macrophages may not be beneficial to the organ since macrophage might revert back to produce injurious effect on the tissues. To explain the lack of effect of exercise on reducing the post-SCI elevation in kidney $\mathrm{CD} 11 \mathrm{~b}$ expression, further investigation is required. One study has shown that 1 hour of hand cycling for 5 days a week at self-paced speed on individuals with SCI at T4-L2 level increases circulatory leucocytes in the post $\mathrm{SCl}$ subjects, and rigorous exercise of high intensity and duration has shown to increase and sustain the level of circulating leucocytes in the body (Allgrove, Chapman, Christides, \& Smith, 2012). High level of circulatory leucocytes for a long duration exposes internal organs to ongoing damage (keeping the macrophage level at or above injured value) and ultimately reverting the protective effects to injurious reaction producing structural and functional loss in the kidneys (Ricardo, van Goor et al. 2008). Additionally, it is possible that the increased level of macrophage may be necessary to bring the TGF $\beta$ level back to normal levels since activation of macrophages are required to synthesize TGF $\beta$ (Assoian et al., 1987), so a reduction of TGF $\beta$ level may induce an increased level of macrophage as a positive feedback. 
$\underline{\text { Impact of training duration on post-SCI kidney functions }}$

Treadmill training as short as 20 minutes to over 1 hour per day has shown to be effective in regaining functions after $\mathrm{SCl}$ as indicated in several studies (discussed above). Exercise or treadmill training improves cardiorespiratory, locomotor, bladder-bowel, sexual functions as well as lower limb blood flow and maintains leg muscle mass. Even though overall body functions show improvement and recovery, examination of type, form and duration of exercise benefits on individual organ systems has not been well studied. The current experiments found no differences in the expression of both TGF $\beta$ and $\mathrm{CD} 11 \mathrm{~b}$ in 30 min and 60 min trained group indicating that the 30 minutes training may be sufficient for bringing TGF $\beta$ expression to near sham values. 


\section{CONCLUSIONS}

TGF $\beta$ is important in immune system homeostasis and tissue recovery. The current results indicate that as little as 30 minutes of daily exercise will reverse SCl-induced changes in TGF $\beta$ expression in the kidneys. However, elevated levels of expression of CD11b in the kidneys post-injury did not benefit from exercise, therefore additional studies are needed. The post-injury increase in CD11b may be due to $\mathrm{M} 2$ producing repair and recovery in the kidney or it can be exercise-induced increase in circulating leucocytes (or other granulocytes/myeloid cells) that has invaded the organ which could lead to additional tissue injury. Alternatively, the CD11b levels could be tied to the improved levels of TGF $\beta$, as discussed. Note that no obvious macroscopic kidney pathology in the experimental rats were observed in the sectioned tissue (preliminary evidence, not included), hence the increased level of CD11b may not be pathological so as to produce tissue injury and dysfunction that exhibits functional damage in this animal model. Further investigation with specific macrophage markers may shed some light as well as additional studies of post $\mathrm{SCl}$ immune functions will be helpful. In the light of current findings and with additional evidence from our previous study on the benefit of LT on lower urinary tract function (Ward et al., 2014), we conclude that TGF $\beta$ may or may not

indicate renal pathology in this experiment but exercise indeed helps with the 
recovery of TGF $\beta$ expression in the kidneys of these animals after SCI. When 30 minutes and 60 minutes were compared with each other, there was no significant difference in the expression of both the markers, suggesting TGF $\beta$ levels in the kidney can benefit from shorter durations of exercise. Further studies are required to determine if the decreased level of TGF $\beta$ influences renal health. Future studies can be directed towards investigating the immunological impact of decreased TGF $\beta$ expression in kidney and its effect on upper and lower urinary tract function; to determine the underlying cause of increase CD11b levels in the injured and trained animals, detailed histopathological study of the kidney with concurrent urinalysis as well as study of CD11b expression by different cells in the kidneys after SCI and LT would be helpful. 


\section{REFERENCES}

1. Abbate, M., et al., Transforming growth factor-beta1 is up-regulated by podocytes in response to excess intraglomerular passage of proteins: a central pathway in progressive glomerulosclerosis. Am J Pathol, 2002. 161(6): p. 2179-93.

2. Alexeeva, N., et al., Comparison of training methods to improve walking in persons with chronic spinal cord injury: a randomized clinical trial. J Spinal Cord Med, 2011. 34(4): p. 362-79.

3. Allgrove, J.E., et al., Immunoendocrine responses of male spinal cord injured athletes to 1-hour self-paced exercise: pilot study. J Rehabil Res Dev, 2012. 49(6): p. 925-33.

4. Al-Saady, N.M., et al., Monocyte expression of tissue factor and adhesion molecules: the link with accelerated coronary artery disease in patients with chronic renal failure. Heart, 1999. 81(2): p. 134-40.

5. Anderson, K.D., Targeting recovery: priorities of the spinal cord-injured population. J Neurotrauma, 2004. 21(10): p. 1371-83.

6. Angeli, C.A., et al., Altering spinal cord excitability enables voluntary movements after chronic complete paralysis in humans. Brain, 2014. 137(Pt 5): p. 1394-409.

7. Ankeny, D.P., Z. Guan, and P.G. Popovich, B cells produce pathogenic antibodies and impair recovery after spinal cord injury in mice. J Clin Invest, 2009. 119(10): p. 2990-9.

8. Ankeny, D.P., et al., Spinal cord injury triggers systemic autoimmunity: evidence for chronic B lymphocyte activation and lupus-like autoantibody synthesis. J Neurochem, 2006. 99(4): p. 1073-87.

9. Assoian, R.K., et al., Expression and secretion of type beta transforming growth factor by activated human macrophages. Proc Natl Acad Sci U S A, 1987. 84(17): p. 6020-4.

10. Awai, L. and A. Curt, Intralimb coordination as a sensitive indicator of motorcontrol impairment after spinal cord injury. Front Hum Neurosci, 2014. 8: p. 148.

11. Balsara, Z.R., et al., Enhanced susceptibility to urinary tract infection in the spinal cord-injured host with neurogenic bladder. Infect Immun, 2013. 81(8): p. 3018-26. 
12. Bao, F., et al., Increased oxidative activity in human blood neutrophils and monocytes after spinal cord injury. Exp Neurol, 2009. 215(2): p. 308-16.

13. Bao, F., et al., CD11d integrin blockade reduces the systemic inflammatory response syndrome after spinal cord injury. Exp Neurol, 2011. 231(2): p. 272-83.

14. Bao, F., et al., The systemic inflammatory response after spinal cord injury in the rat is decreased by alpha4beta1 integrin blockade. J Neurotrauma, 2012. 29(8): p. 1626-37.

15. Barajas, L., L. Liu, and K. Powers, Anatomy of the renal innervation: intrarenal aspects and ganglia of origin. Can J Physiol Pharmacol, 1992. 70(5): p. 735-49.

16. Barbeau, H., et al., Tapping into spinal circuits to restore motor function. Brain Res Brain Res Rev, 1999. 30(1): p. 27-51.

17. Barbeau, H. and S. Rossignol, Recovery of locomotion after chronic spinalization in the adult cat. Brain Res, 1987. 412(1): p. 84-95.

18. Barbeau, H. and S. Rossignol, Enhancement of locomotor recovery following spinal cord injury. Curr Opin Neurol, 1994. 7(6): p. 517-24.

19. Basoni, C., et al., Inhibitory control of TGF- $\beta 1$ on the activation of Rap1, CD11b, and transendothelial migration of leukocytes. The FASEB Journal, 2005.

20. Behrman, A.L., M.G. Bowden, and P.M. Nair, Neuroplasticity after spinal cord injury and training: an emerging paradigm shift in rehabilitation and walking recovery. Phys Ther, 2006. 86(10): p. 1406-25.

21. Behrman, A.L. and S.J. Harkema, Locomotor training after human spinal cord injury: a series of case studies. Phys Ther, 2000. 80(7): p. 688-700.

22. Benevento, B.T. and M.L. Sipski, Neurogenic bladder, neurogenic bowel, and sexual dysfunction in people with spinal cord injury. Phys Ther, 2002. 82(6): p. 601-12.

23. Bizzarini, E., et al., Exercise prescription in subjects with spinal cord injuries. Arch Phys Med Rehabil, 2005. 86(6): p. 1170-5.

24. Border, W.A., et al., Transforming growth factor-beta regulates production of proteoglycans by mesangial cells. Kidney Int, 1990. 37(2): p. 689-95.

25. Brunner, G. and R. Blakytny, Extracellular regulation of TGF-beta activity in wound repair: growth factor latency as a sensor mechanism for injury. Thromb Haemost, 2004. 92(2): p. 253-61.

26. Burr, J.F., R.J. Shephard, and E.P. Zehr, Physical activity after stroke and spinal cord injury: evidence-based recommendations on clearance for physical activity and exercise. Can Fam Physician, 2012. 58(11): p. 1236-9. 
27. Cai, L.L., et al., Plasticity of functional connectivity in the adult spinal cord. Philos Trans R Soc Lond B Biol Sci, 2006. 361(1473): p. 1635-46.

28. Cardenas, D.D. and T.M. Hooton, Urinary tract infection in persons with spinal cord injury. Arch Phys Med Rehabil, 1995. 76(3): p. 272-80.

29. Cazac, B.B. and J. Roes, TGF-beta receptor controls $B$ cell responsiveness and induction of IgA in vivo. Immunity, 2000. 13(4): p. 443-51.

30. De Leon, R.D., et al., Full weight-bearing hindlimb standing following stand training in the adult spinal cat. J Neurophysiol, 1998. 80(1): p. 83-91.

31. Devillard, X., et al., Effects of training programs for spinal cord injury. Ann Readapt Med Phys, 2007. 50(6): p. 490-8, 480-9.

32. Dietz, V., G. Colombo, and L. Jensen, Locomotor activity in spinal man. Lancet, 1994. 344(8932): p. 1260-3.

33. Dobkin, B., et al., Weight-supported treadmill vs over-ground training for walking after acute incomplete SCI. Neurology, 2006. 66(4): p. 484-93.

34. Duffield, J.S., Macrophages and immunologic inflammation of the kidney. Semin Nephrol, 2010. 30(3): p. 234-54.

35. Dumont, R.J., et al., Acute spinal cord injury, part I: pathophysiologic mechanisms. Clin Neuropharmacol, 2001. 24(5): p. 254-64.

36. Edgerton, V.R., et al., Training locomotor networks. Brain Res Rev, 2008. 57(1): p. 241-54.

37. Fehlings, M.G., et al., Early versus delayed decompression for traumatic cervical spinal cord injury: results of the Surgical Timing in Acute Spinal Cord Injury Study (STASCIS). PLoS One, 2012. 7(2): p. e32037.

38. Fehlings, M.G. and J.R. Wilson, Timing of surgical intervention in spinal trauma: what does the evidence indicate? Spine (Phila Pa 1976), 2010. 35(21 Suppl): p. S159-60.

39. Field-Fote, E.C., Combined use of body weight support, functional electric stimulation, and treadmill training to improve walking ability in individuals with chronic incomplete spinal cord injury. Arch Phys Med Rehabil, 2001. 82(6): p. 818-24.

40. Fischer, M.J., et al., Prevalence of chronic kidney disease in patients with spinal cord injuries/disorders. Am J Nephrol, 2012. 36(6): p. 542-8.

41. Fritz, S.L., et al., An intensive intervention for improving gait, balance, and mobility in individuals with chronic incomplete spinal cord injury: a pilot study of activity tolerance and benefits. Arch Phys Med Rehabil, 2011. 92(11): p. 177684. 
42. Frood, R.T., The use of treadmill training to recover locomotor ability in patients with spinal cord injury. Bioscience Horizons, 2011. 4(1): p. 108-117.

43. Fujiu, K., I. Manabe, and R. Nagai, Renal collecting duct epithelial cells regulate inflammation in tubulointerstitial damage in mice. J Clin Invest, 2011. 121(9): p. 3425-41.

44. Garstang, S.V. and S.A. Miller-Smith, Autonomic nervous system dysfunction after spinal cord injury. Phys Med Rehabil Clin N Am, 2007. 18(2): p. 275-96, vivii.

45. Gimenez y Ribotta, M., et al., Strategies for regeneration and repair in spinal cord traumatic injury. Prog Brain Res, 2002. 137: p. 191-212.

46. Goldshmit, Y., et al., Treadmill training after spinal cord hemisection in mice promotes axonal sprouting and synapse formation and improves motor recovery. J Neurotrauma, 2008. 25(5): p. 449-65.

47. Gooch, J.L. and A.C. Sharma, Targeting the immune system to treat hypertension: where are we? Curr Opin Nephrol Hypertens, 2014. 23(5): p. 4739.

48. Gorassini, M.A., et al., Changes in locomotor muscle activity after treadmill training in subjects with incomplete spinal cord injury. J Neurophysiol, 2009. 101(2): p. 969-79.

49. Gorelik, L. and R.A. Flavell, Abrogation of TGFbeta signaling in T cells leads to spontaneous T cell differentiation and autoimmune disease. Immunity, 2000. 12(2): p. 171-81.

50. Goumenos, D.S., et al., Transforming growth factor-beta(1) in the kidney and urine of patients with glomerular disease and proteinuria. Nephrol Dial Transplant, 2002. 17(12): p. 2145-52.

51. Gris, D., E.F. Hamilton, and L.C. Weaver, The systemic inflammatory response after spinal cord injury damages lungs and kidneys. Exp Neurol, 2008. 211(1): p. 259-70.

52. Gupta, D.S. and C.H. Hubscher, Estradiol treatment prevents injury induced enhancement in spinal cord dynorphin expression. Front Physiol, 2012. 3: p. 28.

53. Hagen, E.M., et al., Cardiovascular and urological dysfunction in spinal cord injury. Acta Neurol Scand Suppl, 2011(191): p. 71-8.

54. Harkema, S., et al., Effect of epidural stimulation of the lumbosacral spinal cord on voluntary movement, standing, and assisted stepping after motor complete paraplegia: a case study. Lancet, 2011. 377(9781): p. 1938-47. 
55. Harkema, S.J., et al., Locomotor training: as a treatment of spinal cord injury and in the progression of neurologic rehabilitation. Arch Phys Med Rehabil, 2012. 93(9): p. 1588-97.

56. Harkema, S.J., et al., Balance and ambulation improvements in individuals with chronic incomplete spinal cord injury using locomotor training-based rehabilitation. Arch Phys Med Rehabil, 2012. 93(9): p. 1508-17.

57. Hausmann, O.N., Post-traumatic inflammation following spinal cord injury. Spinal Cord, 2003. 41(7): p. 369-78.

58. Hayes, K.C., et al., Elevated serum titers of proinflammatory cytokines and CNS autoantibodies in patients with chronic spinal cord injury. J Neurotrauma, 2002. 19(6): p. 753-61.

59. Heidari, B., et al., Expression of CD11b as an Adhesion Molecule on Neutrophils in Children with Kawasaki Disease. Iran J Allergy Asthma Immunol, 2014. 13(4): p. 265-70.

60. Heutink, M., et al., Chronic spinal cord injury pain: pharmacological and nonpharmacological treatments and treatment effectiveness. Disabil Rehabil, 2011. 33(5): p. 433-40.

61. Hicks, A.L., et al., Long-term body-weight-supported treadmill training and subsequent follow-up in persons with chronic $\mathrm{SCl}$ : effects on functional walking ability and measures of subjective well-being. Spinal Cord, 2005. 43(5): p. 291-8.

62. Hicks, A.L. and K.A. Ginis, Treadmill training after spinal cord injury: it's not just about the walking. J Rehabil Res Dev, 2008. 45(2): p. 241-8.

63. Horst, M., et al., Multisystem neuroprosthetic training improves bladder function after severe spinal cord injury. J Urol, 2013. 189(2): p. 747-53.

64. Hubscher, C.H., J.D. Fell, and D.S. Gupta, Sex and hormonal variations in the development of at-level allodynia in a rat chronic spinal cord injury model. Neurosci Lett, 2010. 477(3): p. 153-6.

65. Hubscher, C.H. and R.D. Johnson, Effects of acute and chronic midthoracic spinal cord injury on neural circuits for male sexual function. II. Descending pathways. J Neurophysiol, 2000. 83(5): p. 2508-18.

66. Hutchinson, K.J., et al., Three exercise paradigms differentially improve sensory recovery after spinal cord contusion in rats. Brain, 2004. 127(Pt 6): p. 1403-14.

67. Ichiyama, R.M., et al., Step training reinforces specific spinal locomotor circuitry in adult spinal rats. J Neurosci, 2008. 28(29): p. 7370-5.

68. Jacobs, P.L. and M.S. Nash, Exercise recommendations for individuals with spinal cord injury. Sports Med, 2004. 34(11): p. 727-51. 
69. Kawai, K., et al., CD11b-mediated migratory property of peripheral blood B cells. J Allergy Clin Immunol, 2005. 116(1): p. 192-7.

70. Kirshblum, S.C., et al., Spinal cord injury medicine. 3. Rehabilitation phase after acute spinal cord injury. Arch Phys Med Rehabil, 2007. 88(3 Suppl 1): p. S62-70.

71. Koltyn, K.F., Analgesia following exercise: a review. Sports Med, 2000. 29(2): p. 85-98.

72. Krum, H., et al., Diurnal blood pressure variation in quadriplegic chronic spinal cord injury patients. Clin Sci (Lond), 1991. 80(3): p. 271-6.

73. $\mathrm{Ku}, \mathrm{J} . \mathrm{H}$., et al., Complications of the upper urinary tract in patients with spinal cord injury: a long-term follow-up study. Urol Res, 2005. 33(6): p. 435-9.

74. Kuhlemeier, K.V., et al., Renal function after acute and chronic spinal cord injury. J Urol, 1984. 131(3): p. 439-45.

75. Labruyere, R. and H.J. van Hedel, Strength training versus robot-assisted gait training after incomplete spinal cord injury: a randomized pilot study in patients depending on walking assistance. J Neuroeng Rehabil, 2014. 11(1): p. 4.

76. Lan, H.Y., et al., The pathogenic role of macrophage migration inhibitory factor in immunologically induced kidney disease in the rat. J Exp Med, 1997. 185(8): p. 1455-65.

77. Leicht, C.A., V.L. Goosey-Tolfrey, and N.C. Bishop, Spinal cord injury: known and possible influences on the immune response to exercise. Exerc Immunol Rev, 2013. 19: p. 144-63.

78. Li, M.O., S. Sanjabi, and R.A. Flavell, Transforming growth factor-beta controls development, homeostasis, and tolerance of $\mathrm{T}$ cells by regulatory $\mathrm{T}$ celldependent and -independent mechanisms. Immunity, 2006. 25(3): p. 455-71.

79. Lu, L.H., et al., Increased macrophage infiltration and fractalkine expression in cisplatin-induced acute renal failure in mice. J Pharmacol Exp Ther, 2008. 324(1): p. 111-7.

80. Lucareli, P.R., et al., Gait analysis following treadmill training with body weight support versus conventional physical therapy: a prospective randomized controlled single blind study. Spinal Cord, 2011. 49(9): p. 1001-7.

81. Lundell, $H_{\text {., }}$ et al., Cerebral activation is correlated to regional atrophy of the spinal cord and functional motor disability in spinal cord injured individuals. Neuroimage, 2011. 54(2): p. 1254-61.

82. Marie, J.C., D. Liggitt, and A.Y. Rudensky, Cellular mechanisms of fatal earlyonset autoimmunity in mice with the $\mathrm{T}$ cell-specific targeting of transforming growth factor-beta receptor. Immunity, 2006. 25(3): p. 441-54. 
83. Martinez, M., H. Delivet-Mongrain, and S. Rossignol, Treadmill training promotes spinal changes leading to locomotor recovery after partial spinal cord injury in cats. J Neurophysiol, 2013. 109(12): p. 2909-22.

84. Mautes, A.E., et al., Vascular events after spinal cord injury: contribution to secondary pathogenesis. Phys Ther, 2000. 80(7): p. 673-87.

85. Merkler, D., et al., Locomotor recovery in spinal cord-injured rats treated with an antibody neutralizing the myelin-associated neurite growth inhibitor Nogo-A. J Neurosci, 2001. 21(10): p. 3665-73.

86. Middleton, J.W., G. Leong, and L. Mann, Management of spinal cord injury in general practice - part 1. Aust Fam Physician, 2008. 37(4): p. 229-33.

87. Morawietz, C. and F. Moffat, Effects of locomotor training after incomplete spinal cord injury: a systematic review. Arch Phys Med Rehabil, 2013. 94(11): p. 2297308.

88. Moustakas, A., et al., Mechanisms of TGF-beta signaling in regulation of cell growth and differentiation. Immunol Lett, 2002. 82(1-2): p. 85-91.

89. Munger, J.S., et al., Latent transforming growth factor-beta: structural features and mechanisms of activation. Kidney Int, 1997. 51(5): p. 1376-82.

90. Murphy, M.N., et al., Exercise pressor reflex function following acute hemisection of the spinal cord in cats. Front Physiol, 2013. 4: p. 3.

91. Musselman, K.E., et al., Training of walking skills overground and on the treadmill: case series on individuals with incomplete spinal cord injury. Phys Ther, 2009. 89(6): p. 601-11.

92. Nash, M.S., et al., Evaluation of a training program for persons with $\mathrm{SCl}$ paraplegia using the Parastep 1 ambulation system: part 5. Lower extremity blood flow and hyperemic responses to occlusion are augmented by ambulation training. Arch Phys Med Rehabil, 1997. 78(8): p. 808-14.

93. Oudega, M., Inflammatory response after spinal cord injury. Exp Neurol, 2013. 250: p. 151-5.

94. Pagliacci, M.C., et al., A multicentre follow-up of clinical aspects of traumatic spinal cord injury. Spinal Cord, 2007. 45(6): p. 404-10.

95. Popovich, P.G., P. Wei, and B.T. Stokes, Cellular inflammatory response after spinal cord injury in Sprague-Dawley and Lewis rats. J Comp Neurol, 1997. 377(3): p. 443-64.

96. Postans, N.J., et al., Functional electric stimulation to augment partial weightbearing supported treadmill training for patients with acute incomplete spinal cord injury: A pilot study. Arch Phys Med Rehabil, 2004. 85(4): p. 604-10. 
97. Priestley, J.V., et al., Stimulating regeneration in the damaged spinal cord. J Physiol Paris, 2002. 96(1-2): p. 123-33.

98. Rabb, H., et al., Role of CD11a and CD11b in ischemic acute renal failure in rats. Am J Physiol, 1994. 267(6 Pt 2): p. F1052-8.

99. Raineteau, O. and M.E. Schwab, Plasticity of motor systems after incomplete spinal cord injury. Nat Rev Neurosci, 2001. 2(4): p. 263-73.

100. Raslan, A.M. and A.N. Nemecek, Controversies in the surgical management of spinal cord injuries. Neurol Res Int, 2012. 2012: p. 417834.

101. Ricardo, S.D., H. van Goor, and A.A. Eddy, Macrophage diversity in renal injury and repair. J Clin Invest, 2008. 118(11): p. 3522-30.

102. Richardson, P.M., U.M. McGuinness, and A.J. Aguayo, Axons from CNS neurons regenerate into PNS grafts. Nature, 1980. 284(5753): p. 264-5.

103. Rodriguez-Romero, V., et al., Changes in renal function during acute spinal cord injury: implications for pharmacotherapy. Spinal Cord, 2013. 51(7): p. 528-31.

104. Schalow, G., Cure of urinary bladder functions in severe (95\%) motoric complete cervical spinal cord injury in human. Electromyogr Clin Neurophysiol, 2010. 50(34): p. 155-79.

105. Schmid, P., et al., Enhanced expression of transforming growth factor-beta type I and type II receptors in wound granulation tissue and hypertrophic scar. Am J Pathol, 1998. 152(2): p. 485-93.

106. Sharif, H., et al., Effects of FES-Ambulation Training on Locomotor Function and Health-Related Quality of Life in Individuals With Spinal Cord Injury. Top Spinal Cord Inj Rehabil, 2014. 20(1): p. 58-69.

107. Shin, H.Y., et al., Molecular and cellular changes in the lumbar spinal cord following thoracic injury: regulation by treadmill locomotor training. PLoS One, 2014. 9(2): p. e88215.

108. Sinescu, C., et al., Molecular basis of vascular events following spinal cord injury. J Med Life, 2010. 3(3): p. 254-61.

109. Stagg, N.J., et al., Regular exercise reverses sensory hypersensitivity in a rat neuropathic pain model: role of endogenous opioids. Anesthesiology, 2011. 114(4): p. 940-8.

110. Stewart, B.G., et al., Treadmill training-induced adaptations in muscle phenotype in persons with incomplete spinal cord injury. Muscle Nerve, 2004. 30(1): p. 61-8.

111. Swinnen, E., et al., Effectiveness of robot-assisted gait training in persons with spinal cord injury: a systematic review. J Rehabil Med, 2010. 42(6): p. 520-6. 
112. Thijssen, D.H., et al., Rapid vascular adaptations to training and detraining in persons with spinal cord injury. Arch Phys Med Rehabil, 2006. 87(4): p. 474-81.

113. Thomas, S.L. and M.A. Gorassini, Increases in corticospinal tract function by treadmill training after incomplete spinal cord injury. J Neurophysiol, 2005. 94(4): p. 2844-55.

114. Thylen, P., et al., Impaired monocyte CD11b expression in interstitial inflammation in hemodialysis patients. Kidney Int, 2000. 57(5): p. 2099-106.

115. Tribe, C.R., Causes of Death in the Early and Late Stages of Paraplegia. Paraplegia, 1963. 1: p. 19-47.

116. Turiel, M., et al., Robotic treadmill training improves cardiovascular function in spinal cord injury patients. Int J Cardiol, 2011. 149(3): p. 323-9.

117. Varga, G., et al., Active MAC-1 (CD11b/CD18) on DCs inhibits full T-cell activation. Blood, 2007. 109(2): p. 661-9.

118. Wan, M., et al., Injury-activated transforming growth factor beta controls mobilization of mesenchymal stem cells for tissue remodeling. Stem Cells, 2012. 30(11): p. 2498-511.

119. Wan, Y.Y. and R.A. Flavell, TGF-beta and regulatory $T$ cell in immunity and autoimmunity. J Clin Immunol, 2008. 28(6): p. 647-59.

120. Wang, Y. and D.C. Harris, Macrophages in renal disease. J Am Soc Nephrol, 2011. 22(1): p. 21-7.

121. Ward, P.J., et al., Novel Multi-System Functional Gains via Task Specific Training in Spinal Cord Injured Male Rats. J Neurotrauma, 2014. 31(9): p. 81933.

122. Ward, P.J. and C.H. Hubscher, Persistent polyuria in a rat spinal contusion model. J Neurotrauma, 2012. 29(15): p. 2490-8.

123. Warms, C.A., et al., Treatments for chronic pain associated with spinal cord injuries: many are tried, few are helpful. Clin J Pain, 2002. 18(3): p. 154-63.

124. Weld, K.J., et al., INFLUENCES ON RENAL FUNCTION IN CHRONIC SPINAL CORD INJURED PATIENTS. The Journal of Urology, 2000. 164(5): p. 14901493.

125. Wernig, A. and S. Muller, Laufband locomotion with body weight support improved walking in persons with severe spinal cord injuries. Paraplegia, 1992. 30(4): p. 229-38.

126. Wilson, J.R., et al., Early versus late surgery for traumatic spinal cord injury: the results of a prospective Canadian cohort study. Spinal Cord, 2012. 50(11): p. 840-3. 
127. Winchester, P., et al., Changes in supraspinal activation patterns following robotic locomotor therapy in motor-incomplete spinal cord injury. Neurorehabil Neural Repair, 2005. 19(4): p. 313-24.

128. Wirz, M., et al., Effectiveness of automated locomotor training in patients with chronic incomplete spinal cord injury: a multicenter trial. Arch Phys Med Rehabil, 2005. 86(4): p. 672-80.

129. Wright, S.D., et al., Complement receptor type three (CD11b/CD18) of human polymorphonuclear leukocytes recognizes fibrinogen. Proc Natl Acad Sci U S A, 1988. 85(20): p. 7734-8.

130. Wrzesinski, S.H., Y.Y. Wan, and R.A. Flavell, Transforming growth factor-beta and the immune response: implications for anticancer therapy. Clin Cancer Res, 2007. 13(18 Pt 1): p. 5262-70.

131. Wu, M., et al., Robotic resistance treadmill training improves locomotor function in human spinal cord injury: a pilot study. Arch Phys Med Rehabil, 2012. 93(5): p. 782-9.

132. Yoshimura, N., et al., Neural Mechanisms Underlying Lower Urinary Tract Dysfunction. Korean J Urol, 2014. 55(2): p. 81-90.

133. Yu, L., et al., TGF-beta isoforms in renal fibrogenesis. Kidney Int, 2003. 64(3): p. 844-56.

134. Zaluska, W.T., A. Ksiazek, and J. Roliski, Effect of vitamin E modified cellulose membrane on human lymphocyte, monocyte, and granulocyte CD11b/CD18 adhesion molecule expression during hemodialysis. ASAIO J, 2001. 47(6): p. 619-22.

135. Zhang, Y., et al., Autonomic dysreflexia causes chronic immune sup ression after spinal cord injury. J Neurosci, 2013. 33(32): p. 12970-81.

136. Zhou, T.B., et al., Association of PAX2 with cell apoptosis in unilateral ureteral obstruction rats. Ren Fail, 2012. 34(2): p. 194-202.

137. Christopher and Dana Reeve Foundations.www.christopherreeve.org.

138. Mayo Clinics. Shepherd Center. Atlanta, GA. www.mayoclinic.org.

139. Spinal cord injury rehabilitation center, Kessler institute for rehabilitation, New Jersey. www.kessler-rehab.com.

140. National Spinal Cord Injury Statistical Center, Facts and Figures at a Glance. Birmingham, AL: University of Alabama at Birmingham, March 2013. https://www.nscisc.uab.edu/fact \&figures. 


\section{CURRICULUM VITAE}

NAME: $\quad$ Pradeepa Poudyal

ADDRESS: $\quad$ Department of Anatomical Sciences and Neurobiology

511 S Floyd Street R\# 111

University of Louisville

Louisville, KY 40202

EDUCATION \&

TRAINING:

I.Sc. (Intermediate in Science)

Tribhuvan University

Kathmandu, Nepal

June 1994

M.B.B.S (Bachelor of Medicine Bachelor of Surgery)

Calcutta University. Kolkata, India

October 2002

MS (Anatomical Sciences and Neurobiology)

University of Louisville

November 2014

AWARDS: $\quad$ Excellent student scholarship (Grade 6-10, Bhanu Bhakta Memorial Secondary School, Kathmandu) (1987-1992)

Excellent student tuition and books scholarship (2 years in I.Sc, Awarded by National Trading Ltd, Kathmandu) (1992-1994) 